\title{
SECAGEM E ARMAZENAMENTO DE SEMENTES DE MARACUJÁ AMARELO (Passiflora edulis Sims f. flavicarpa Degener) $^{1}$
}

\author{
VINICIUS DE OLIVEIRA CARLESSO ${ }^{2}$, PEDRO AMORIM BERBERT ${ }^{3}$, ROBERTO FERREIRA DA SILVA $^{4}$, EDENIO DETMANN ${ }^{5}$
}

\begin{abstract}
RESUMO - Este trabalho foi desenvolvido com os objetivos de avaliar os efeitos imediato e latente da temperatura de secagem e de dois tipos de embalagem sobre a qualidade fisiológica de sementes de maracujá-amarelo após três e seis meses de armazenamento. Empregaram-se quatro níveis de temperatura do ar de secagem (ambiente à sombra, 30, 35 e $40{ }^{\circ} \mathrm{C}$ ), um nível de fluxo de ar, $48 \mathrm{~m}^{3}$ $\mathrm{min}^{-1} \mathrm{~m}^{-2}$, e teores de água inicial e final de cerca de 35 e $10 \%$ b.u., respectivamente. Os tratamentos de secagem foram realizados em protótipo de secador de leito fixo, em camada delgada, com fluxo de ar ascendente. Avaliou-se a qualidade fisiológica por meio de testes de germinação e vigor. Depois da secagem, as sementes foram embaladas e armazenadas em câmara do tipo B.O.D. a $15 \pm 1{ }^{\circ} \mathrm{C}$. As temperaturas utilizadas na secagem das sementes não influenciam a germinação. $\mathrm{O}$ armazenamento por três e seis meses não afetou a qualidade fisiológica das sementes. A secagem das sementes de mamão pode ser realizada à sombra ou em temperaturas de 30 a $40{ }^{\circ} \mathrm{C}$ sem afetar a qualidade fisiológica das mesmas.
\end{abstract}

Termos para indexação: Passiflora edulis, maracujá, sementes, secagem, armazenamento, qualidade

\section{DRYING AND STORAGE OF SEEDS OF THE YELLOW PASSION FRUIT (Passiflora edulis \\ Sims $f$. flavicarpa Degener)}

\begin{abstract}
This study had the following objects: To evaluate the immediate and latent effects of drying-air temperature and compare the influence of two types of seed packaging on the physiological quality of seeds of the yellow passion fruit. Tests were conducted employing four levels of drying-air temperature (ambient temperature under shade, 30, 35, and $40^{\circ} \mathrm{C}$ ), one level of drying-air airflow (48 $\mathrm{m}^{3} \mathrm{~min}^{-1} \mathrm{~m}^{-2}$ ), and initial and final seed moisture contents of 35 and $10 \%$ w.b., respectively. Drying runs were performed in thin layers in a prototype laboratory drier with an upward airflow design. The physiological quality of the seeds was assessed through vigour and standard germination tests. Upon removal from the drier, seeds were cooled to ambient air temperature, placed in glass containers and polyethylene bags and stored in a controlled temperature chamber at $15 \pm 1{ }^{\circ} \mathrm{C}$ for 90 and 180 days. Results showed that drying-air temperature had no significant effect on passion fruit seeds germination. Storage priods of 90 and 180 days produced seeds with the same vigour based on the count made at the seventh day. Also, the final germination count was not affected by storage time. Results revealed that both seed vigour and germination were the same regardless of whether they
\end{abstract}

${ }^{1}$ Aceito para publicação em18/05/2007. Aceito para publicação 24/01/2008. Extraído da Dissertação de Mestrado do primeiro autor, apresentada à UENF. Trabalho financiado pelo CNPq, FAPERJ, FINEP e International Foundation for Science (IFS). ${ }^{2}$ Eng Agrônomo, M.S., Laboratório de Engenharia Agrícola (LEAG), Universidade Estadual do Norte Fluminense Darcy Ribeiro (UENF), CEP 28013-602 Campos dos Goytacazes, RJ.
E-mail: carlesso@uenf.br. ${ }^{3}$ Professor Associado, Ph.D., LEAG/UENF. E-mail: pberbert@uenf.br. ${ }^{4}$ Professor Titular, Ph.D., Laboratório de Fitotecnia (LFIT), UENF, E-mail: roberto@uenf.br. 'Professor, D.S., Departamento de Zootecnia, Universidade Federal de Viçosa (UFV), CEP 36571-000 Viçosa, MG. E-mail: detmann@ufv.br 
were dried at ambient temperature under shade or under controlled temperature in the range from 30 to $40^{\circ} \mathrm{C}$.

Index terms: Passiflora edulis, passion fruit, seeds, drying, storage, physiological quality

\section{INTRODUÇÃO}

O Brasil se destaca como o principal produtor de maracujá do mundo; no entanto, o mercado internacional de polpa e de suco concentrado é dominado pelo Equador, Colômbia e Peru, sendo a Alemanha e a Holanda os principais países importadores desses produtos. Em se tratando do mercado de fruto in natura, Colômbia, Brasil e Venezuela são os maiores produtores de frutos de cor amarela (Souza et al., 2002).

A principal forma de propagação do maracujazeiro é a sexuada, ou seja, via seminífera. Pode-se afirmar que na quase totalidade dos casos de plantios comerciais, os pomares são formados a partir de mudas geradas de sementes. Observase que, em geral, essas mudas podem ser transportadas definitivamente para o campo com até quatro meses de antecedência em relação àquelas formadas por enxertia. No entanto, tem-se constatado que em até 17 semanas depois do plantio das mudas no campo, não há diferença no crescimento do maracujazeiro em função do método de propagação utilizado. Sendo assim, apesar de as mudas formadas a partir de sementes serem mais vigorosas e garantirem maior diversidade genética ao pomar que as mudas formadas por via vegetativa, o crescimento da cultura no campo independe do método de propagação (Almeida et al., 1991; Lima e Trindade, 2002). Muitas vezes a propagação é realizada sem que se tenha preocupação com os critérios de seleção dessas sementes. Além disso, as sementes são geralmente secas à sombra ou pleno sol, sem que haja controle em relação às condições de temperatura, umidade relativa (UR) e vazão específica do ar de secagem. Como conseqüência, isso pode acarretar baixa porcentagem de germinação das sementes ou plantas pouco vigorosas, baixa produtividade da lavoura e grande variabilidade nas características físicas dos frutos, fatores esses indesejáveis por parte dos produtores. Devido a este fato torna-se importante conhecer as melhores e mais eficientes técnicas de secagem das sementes.

Enquanto para as sementes de cereais e oleaginosas é possível encontrar informações na literatura a respeito da influência dos parâmetros de secagem sobre sua qualidade fisiológica, para as sementes de fruteiras, apesar da grande demanda por informações, as pesquisas são escassas. Estudos sobre o pré-processamento, são ainda incipientes, não apresentando resultados além daqueles obtidos em estufas de secagem com convecção natural ou forçada, em que, além da temperatura, não há o controle efetivo das demais variáveis envolvidas no processo.

O teor de água das sementes de maracujá, após terem sido extraídas dos frutos e lavadas, encontra-se geralmente em torno de $30 \%$ b.u. Sabe-se que o armazenamento de sementes por períodos prolongados e com teores de água elevados é praticamente inviável, pois nessas condições o metabolismo das sementes continua intenso. Portanto, além da secagem, outro fator importante na produção de mudas a partir de sementes é o seu armazenamento. Piza Júnior (1991), citado por Bruckner e Picanço (2001), relata que até o quinto mês a partir da extração das sementes, a perda do poder germinativo é lenta, tornando-se mais rápida a partir daí; aos 12 meses o poder germinativo já é muito baixo. Ruggiero (1998) obteve resultados divergentes, recomendando que se utilizem sementes novas, pois o poder germinativo das sementes dessa cultura decairia muito rapidamente, podendo passar de cerca de $90 \%$ logo depois da colheita para valores inferiores a $20 \%$ após seis meses de armazenamento.

Almeida et al. (1987) concluíram que sementes conservadas em condição ambiente e armazenadas em sacos de papel, apresentaram, após um período de 12 meses, porcentagem de germinação igual a zero. Nakagawa et al. (1991), estudando diferentes condições de armazenamento de sementes de maracujá com percentagem inicial de germinação de $75 \%$, observaram que aquelas armazenadas em câmara fria a cerca de $5{ }^{\circ} \mathrm{C}$ e embaladas em saco duplo de polietileno, apresentaram resultados mais satisfatórios que as sementes submetidas aos outros tratamentos (ambiente natural de laboratório e câmara seca com UR de aproximadamente $40 \%$ ), chegando ao final do período com cerca de 5 anos de armazenamento, com porcentagem de germinação de $60 \%$. As sementes foram secadas à sombra por 10 dias e apresentavam teor de água igual a $9,6 \%$ b.u.

Oliveira et al. (1984) trabalharam com sementes de maracujá colhidas desde o ano de 1972 até 1982, exceto 1974. Estas sementes foram armazenadas em câmara seca à temperatura ambiente, UR controlada entre 40 e $45 \%$ e embaladas em sacolas de papel. Concluíram que sementes armazenadas durante cinco anos ainda mostravam-se viáveis 
e que a idade das sementes influencia efetivamente na capacidade de emergência e no vigor.

Catunda et al. (2003), depois de secarem sementes de maracujá até teores finais de água de 8 e $10 \%$ b.u., as armazenaram em diferentes condições por 10 meses: refrigerador a $4{ }^{\circ} \mathrm{C}$ e UR igual a $60 \%$; câmara do tipo BOD a $18{ }^{\circ} \mathrm{C}$ e UR igual a $24 \%$ e, finalmente, estocagem em ambiente de laboratório, utilizando, em todos os tratamentos, embalagens semi-permeáveis e impermeáveis. Concluíram que para o período de 10 meses de armazenamento, o ambiente de refrigerador foi o mais adequado e que para o armazenamento das sementes com teor de água de $10 \%$ b.u. em condições de laboratório, a embalagem impermeável foi inadequada.

Martins et al. (2005), ao estudarem o efeito de cinco níveis de teor de água $(26,20,14,10$ e $8 \%$ b.u.) e dois níveis de temperatura $\left(10\right.$ e $\left.20^{\circ} \mathrm{C}\right)$ sobre o comportamento de sementes de maracujá amarelo durante 315 dias de armazenamento, verificaram que a conservação foi favorecida para sementes estocadas com teor de água de $10 \%$ b.u a $20^{\circ} \mathrm{C}$.

Verifica-se, portanto, que além da falta de informações sobre o processo de secagem, existe também uma relação que precisa ser melhor avaliada, que é aquela existente entre as condições de armazenamento e o período de viabilidade das sementes de maracujá-amarelo, de forma a estender esse período e proporcionar um produto final de melhor qualidade.

Diante desse quadro, procurou-se, no presente trabalho, avaliar os efeitos imediato e latente da temperatura de secagem sobre a qualidade fisiológica das sementes de maracujá amarelo e determinar o efeito de dois tipos de embalagem na conservação das sementes no armazenamento.

\section{MATERIAL E MÉTODOS}

O trabalho foi realizado nos Laboratórios de Engenharia Agrícola (LEAG) e de Fitotecnia (LFIT) da Universidade Estadual do Norte Fluminense Darci Ribeiro (UENF), Campos dos Goytacazes, RJ. Para os testes de avaliação do efeito da temperatura de secagem e das condições de armazenamento foram utilizadas sementes de maracujá amarelo (Passiflora edulis Sims f. flavicarpa Degener), provenientes de plantio comercial na Fazenda Rancho Lugavi, Campos dos Goytacazes, RJ. Os frutos foram recolhidos do chão quando estavam maduros e amarelo-esverdeados, sendo imediatamente transportados para o LEAG, onde foram cortados na região próxima ao pedúnculo e paralelamente ao seu eixo equatorial. Posteriormente, cerca de 500 a 600 $\mathrm{mL}$ de sementes, juntamente com restos placentários, arilo e o suco dos frutos, foram transferidos para um despolpador adaptado a um liquidificador. Adicionou-se então à polpa volume complementar de $100 \mathrm{~mL}$ de água destilada. O aparelho da marca Arno S.A., modelo BA/BSA, série RC, de $300 \mathrm{~W}$ foi acionado em baixa rotação por cerca de $120 \mathrm{~s}$.

Em seguida, as sementes foram transferidas para uma peneira com malha de aço onde foram lavadas em água corrente até eliminar totalmente o arilo. Depois da lavagem, as sementes permaneceram espalhadas na peneira por um período de aproximadamente $30 \mathrm{~min}$, à temperatura ambiente, para remoção da água superficial. Logo após, foram transferidas para frascos de vidro de $3275 \mathrm{~mL}$, com tampa de plástico rosqueável, vedados com Parafilm. Os frascos com as sementes foram devidamente identificados e acondicionados em câmara do tipo B.O.D. com temperatura controlada em $4 \pm 1{ }^{\circ} \mathrm{C}$ até serem retiradas para os testes de secagem.

O teor de água inicial das sementes foi determinado antes de se iniciar cada teste de secagem, a $130 \pm 1{ }^{\circ} \mathrm{C}$ por $1 \mathrm{~h}$ (Brasil, 1992). Os testes de secagem das sementes de maracujá foram realizados utilizando-se um secador protótipo de camada delgada, capaz de fornecer o ar de secagem em condições controladas de temperatura e vazão. Este secador possui uma câmara de secagem, que é composta por três bandejas circulares de diâmetro interno igual a 0,25 m, com fundo perfurado em malha de aço inoxidável.

Amostras com teor de água de $34,8 \%$ b.u. e contendo $\cong$ 120 g de sementes em equilíbrio térmico com o ar ambiente foram então colocadas em cada uma das bandejas, sendo então espalhadas sobre o fundo perfurado, de maneira a formar camadas finas com altura correspondente à espessura média das sementes. Em todos os testes, a redução do teor de água das sementes foi monitorada por gravimetria, pesando-se o conjunto bandeja-amostra em intervalos regulares de $5 \mathrm{~min}$ na primeira $1 / 2$ hora, de $10 \mathrm{~min}$ até os $120 \mathrm{~min}$, de $15 \mathrm{~min}$ de 120 até 180 min e de 30 min a partir de 180 min, utilizandose uma balança digital com grau de acurácia de $0,01 \mathrm{~kg}$. Além da secagem à sombra (testemunha), foram analisados três níveis de temperatura do ar de secagem, 30,35 e $40{ }^{\circ} \mathrm{C}$ e o fluxo de ar foi de aproximadamente $48 \mathrm{~m}^{3} \mathrm{~min}^{-1} \mathrm{~m}^{-2}$, o que corresponde a uma velocidade de aproximadamente 0,8 $\mathrm{m} \mathrm{s}^{-1}$. A secagem foi interrompida quando o teor de água do produto atingiu o valor de $10 \%$ b.u.

O monitoramento da velocidade do ar de secagem foi realizado utilizando-se um anemômetro de pás rotativas Airflow, modelo AV6, e o da temperatura foi realizado utilizando-se um termômetro de mercúrio com divisão da escala igual a $1{ }^{\circ} \mathrm{C}$, localizado abaixo da câmara de secagem. As leituras de velocidade e temperatura do ar de 
secagem foram registradas antes de se retirar as bandejas em cada procedimento de pesagem. A temperatura e umidade relativa do ar ambiente foram medidas com um termohigrômetro digital Hygrometer - Series 485, fabricado pela Dwyer Instruments, Inc. e registrados continuamente em termohigrógrafo SATO do tipo SIGMA II, modelo NS II-Q. A intenção deste monitoramento foi de determinar as demais propriedades psicrométricas do ar de secagem, utilizando o programa computacional GRAPSI desenvolvido por Melo et al. (2004).

Terminada a secagem, parte da amostra foi utilizada para determinação do teor de água final e outra parte foi utilizada para realização dos testes de qualidade fisiológica. $\mathrm{O}$ poder germinativo e o vigor das sementes foram avaliados imediatamente depois da secagem, para determinação do efeito imediato da temperatura do ar sobre a germinação; e em períodos regulares de armazenamento, para verificação do seu efeito latente. O restante das sementes secadas foi subdividido em quatro porções com aproximadamente a mesma massa, sendo duas acondicionadas em frascos de vidro de $150 \mathrm{~mL}$, com tampa rosqueável e vedados com Parafilm; e duas colocadas em sacos plásticos de polietileno do tipo Ziplock. As sementes acondicionadas foram armazenadas em câmara do tipo B.O.D. a $15 \pm 1{ }^{\circ} \mathrm{C}$. Estas amostras foram utilizadas para realização dos testes de avaliação da qualidade fisiológica das sementes em função da temperatura de secagem e do período de armazenamento, ou seja, aos 90 e 180 dias. Para determinar a ocorrência de variação de umidade ao longo do tempo, o teor de água foi determinado ao final de cada período de armazenamento.

O teste de germinação foi realizado de acordo com as Regras para Análise de Sementes (Brasil, 1992). Para avaliação do vigor, além dos resultados da primeira contagem do teste de germinação, foi realizada outra contagem no $14^{\circ}$ dia, onde quantificou-se o número de plântulas normais fortes, plântulas normais fracas, plântulas anormais e sementes deterioradas. Classificou-se como plântulas normais fortes aquelas que se apresentavam vigorosas, com parte aérea e sistema radicular bem desenvolvidos e tamanho do hipocótilo igual ou superior a $2,5 \mathrm{~cm}$. Como normais fracas foram classificadas as plântulas que se apresentaram pouco vigorosas, com tamanho do hipocótilo inferior a 2,5 $\mathrm{cm}$, e como plântulas anormais as que apresentaram qualquer anormalidade e/ou ausência de alguma das partes vegetativas (raiz, hipocótilo ou cotilédones). Foram classificadas como sementes deterioradas as sementes que não estavam duras nem dormentes, apresentando-se amolecidas e atacadas por fungos.
O experimento para avaliação do efeito da temperatura do ar de secagem sobre a qualidade fisiológica das sementes foi realizado segundo delineamento em quadrado latino $4 \mathrm{x}$ 4 , com três repetições, onde as linhas representavam os lotes de sementes e as colunas o número de dias (1, 2, 3 e 4) em que as sementes permaneceram estocadas antes da secagem. Os dados experimentais foram avaliados por meio de análise de variância e regressão. A análise foi dividida em três partes, sendo que na primeira os tratamentos corresponderam às condições de secagem, as linhas corresponderam aos lotes de sementes e as colunas aos dias de armazenamento até serem secadas. A segunda foi feita em esquema de subdivisão de parcelas em função das embalagens. A terceira foi feita em esquema de subdivisão de parcelas em arranjo fatorial 2 x 2 (dois tipos de embalagem e dois períodos de armazenamento). Os dados foram interpretados por meio de análise de variância e regressão. As médias dos tratamentos foram comparadas com a média da testemunha, secagem à sombra, aplicandose o teste de Dunnett a $5 \%$ de probabilidade. A comparação entre tratamentos foi realizada por intermédio de contrastes ortogonais.

Em complemento ao experimento anterior, realizouse um segundo experimento em que foram avaliados as temperaturas de secagem, o período de armazenamento e os tipos de embalagem. Este segundo experimento foi realizado em delineamento inteiramente casualizado, num esquema fatorial $4 \times 3 \times 2$, com 4 repetições. Os resultados foram submetidos a análise de variância e aos testes de comparação de médias para fatores qualitativos (embalagem) e análise de regressão polinomial para os quantitativos (período de armazenamento).

As variáveis estudadas foram abreviadas da seguinte maneira: $1^{\text {a }}$ contagem = percentual de sementes que emitiram a raiz primária aos sete dias (vigor), \%; Vigor das plântulas = percentual de plântulas normais fortes aos 14 dias (vigor), \%; Germinação = percentual de germinação aos 28 dias, \%; ADS = teor de água das sementes imediatamente depois da secagem; \% b.u.; AD90 = teor de água das sementes depois de 90 dias de armazenamento, \% b.u.; AD180 = teor de água das sementes depois de 180 dias de armazenamento, \% b.u.

\section{RESULTADOS E DISCUSSÃO}

Os valores médios de temperatura e razão da mistura do ar ambiente, as condições iniciais do produto e os parâmetros de secagem utilizados nos testes experimentais para avaliação da qualidade fisiológica das sementes de maracujá encontramse na Tabela 1. 
TABELA 1. Condições médias do ar e das sementes de maracujá para os seguintes tratamentos: secagem à temperatura ambiente, 30, 35 e $40{ }^{\circ} \mathrm{C}$ e tempo de secagem, para velocidade de $0,8 \mathrm{~m} \mathrm{~s}^{-1}$ e teor de água inicial de $34,8 \%$ b.u.

Teste

$1 * \quad 2 *$

3*

4*

5

6

7

8

Condições do ar ambiente:

\begin{tabular}{|c|c|c|c|c|c|c|c|c|}
\hline Temperatura, ${ }^{\circ} \mathrm{C}$ & 29,80 & 26,89 & 29,58 & 28,89 & 31,20 & 28,40 & 29,68 & 30,86 \\
\hline Razão da mistura, kgkg $^{-1}$ & 0,0182 & 0,0152 & 0,0196 & 0,0196 & 0,0176 & 0,0162 & 0,0169 & 0,0194 \\
\hline \multicolumn{9}{|l|}{ Condições do ar de secagem: } \\
\hline Temperatura, ${ }^{\circ} \mathrm{C}$ & 29,80 & 26,89 & 29,58 & 28,89 & 30,30 & 30,34 & 30,76 & 29,96 \\
\hline Velocidade do ar, $\mathrm{m} \mathrm{s}^{-1}$ & 0,14 & 0,13 & 0,22 & 0,07 & 0,78 & 0,75 & 0,77 & 0,77 \\
\hline Vazão específica, $\mathrm{m}^{3} \mathrm{~s}^{-1} \mathrm{~m}^{-2}$ & - & - & - & - & 46,99 & 45,15 & 46,17 & 46,42 \\
\hline \multicolumn{9}{|l|}{ Condições iniciais do produto: } \\
\hline Temperatura ${ }^{\circ} \mathrm{C}$ & 29,80 & 26,89 & 29,58 & 28,89 & 31,20 & 28,40 & 29,68 & 30,86 \\
\hline Teor de água, $\%$ b.u. & 34,54 & 35,67 & 32,96 & 33,52 & 33,52 & 37,08 & 33,06 & 35,92 \\
\hline \multicolumn{9}{|l|}{ Condições finais do produto: } \\
\hline Teor de água, \% b.u. & 10,57 & 9,98 & 10,87 & 11,87 & 10,40 & 8,89 & 10,06 & 10,02 \\
\hline Tempo de secagem, $\mathrm{h}$ & 6,50 & 6,38 & 5,53 & 4,83 & 2,37 & 3,44 & 2,07 & 5,50 \\
\hline Teste & 9 & 10 & 11 & 12 & 13 & 14 & 15 & 16 \\
\hline
\end{tabular}

Condições do ar ambiente:

\begin{tabular}{lcccccccc}
\hline Temperatura, ${ }^{\circ} \mathrm{C}$ & 29,58 & 27,65 & 30,92 & 31,56 & 31,03 & 28,27 & 30,62 & 32,96 \\
\hline Razão da mistura, $\mathrm{kgkg}^{-1}$ & 0,0196 & 0,0144 & 0,0140 & 0,0202 & 0,0194 & 0,0146 & 0,0152 & 0,0190 \\
\hline Condições do ar de secagem: & & & & & & & & \\
\hline Temperatura, ${ }^{\circ} \mathrm{C}$ & 34,40 & 35,09 & 35,43 & 35,06 & 38,80 & 39,07 & 39,86 & 39,91 \\
\hline Velocidade do ar, $\mathrm{m} \mathrm{s}^{-1}$ & 0,78 & 0,77 & 0,78 & 0,78 & 0,78 & 0,79 & 0,79 & 0,79 \\
\hline Vazão específica, $\mathrm{m}^{3} \mathrm{~s}^{-1} \mathrm{~m}^{-2}$ & 46,77 & 46,47 & 46,81 & 47,05 & 46,97 & 47,44 & 47,62 & 47,54 \\
\hline Condições iniciais do produto: & & & & & & & & \\
\hline Temperatura ${ }^{\circ} \mathrm{C}$ & 29,58 & 27,65 & 30,92 & 31,56 & 31,03 & 28,27 & 30,62 & 32,96 \\
\hline Teor de água, \% b.u. & 34,00 & 35,11 & 35,06 & 34,75 & 33,73 & 36,75 & 35,01 & 35,33 \\
\hline Condições finais do produto: & & & & & & & & \\
\hline Teor de água, \% b.u. & 10,38 & 9,69 & 8,56 & 9,66 & 10,88 & 9,03 & 8,42 & 10,07 \\
\hline Tempo de secagem, h & 1,30 & 1,14 & 1,54 & 2,12 & 0,75 & 1,10 & 0,97 & 1,11 \\
\hline * secagem à sombra
\end{tabular}

Apresenta-se, na Tabela 2, os dados referentes ao vigor das plântulas e percentual de germinação, estimados aos 14 e 28 dias, respectivamente, e a estimativa do vigor das sementes, feita na primeira contagem (7 dias), realizado com sementes antes e imediatamente depois da secagem. 
TABELA 2 . Resultados do teste de germinação de sementes de maracujá antes (dia zero) e depois da secagem (dias 1, 2 e 3): vigor das plântulas aos 14 dias, percentual de germinação aos 28 dias e vigor das sementes aos 7 dias $\left(1^{\text {a }}\right.$ contagem).

\begin{tabular}{|c|c|c|c|c|c|}
\hline Bloco* & Dia & Temperatura de secagem $\left({ }^{\circ} \mathrm{C}\right)$ & $\begin{array}{c}1^{\mathrm{a}} \text { contagem } \\
(\%)\end{array}$ & $\begin{array}{c}\text { Vigor das } \\
\text { Plântulas } \\
(\%)\end{array}$ & $\begin{array}{c}\text { Germinação } \\
(\%)\end{array}$ \\
\hline 1 & 0 & sem secar & 40,0 & 20,0 & 92,0 \\
\hline 1 & 1 & 35 & 7,0 & 7,5 & 69,5 \\
\hline 1 & 2 & 30 & 4,5 & 5,0 & 78,0 \\
\hline 1 & 3 & $28,8 * *$ & 2,5 & 8,5 & 94,5 \\
\hline 1 & 4 & 40 & 22,0 & 19,0 & 93,0 \\
\hline 2 & 0 & sem secar & 17,0 & 11,0 & 95,0 \\
\hline 2 & 1 & $28,9 * *$ & 12,0 & 17,0 & 94,0 \\
\hline 2 & 2 & 40 & 52,0 & 26,0 & 94,5 \\
\hline 2 & 3 & 35 & 50,5 & 25,5 & 95,5 \\
\hline 2 & 4 & 30 & 40,0 & 13,0 & 96,5 \\
\hline 3 & 0 & sem secar & 7,0 & 9,0 & 93,0 \\
\hline 3 & 1 & 40 & 22,5 & 21,0 & 94,5 \\
\hline 3 & 2 & 35 & 37,0 & 29,0 & 95,5 \\
\hline 3 & 3 & 30 & 31,0 & 21,0 & 94,0 \\
\hline 3 & 4 & $28,8^{* *}$ & 42,5 & 29,0 & 94,0 \\
\hline 4 & 0 & sem secar & 9,0 & 8,0 & 96,0 \\
\hline 4 & 1 & 30 & 19,5 & 10,0 & 96,5 \\
\hline 4 & 2 & $28,8^{* *}$ & 27,0 & 17,0 & 91,0 \\
\hline 4 & 3 & 40 & 56,0 & 39,5 & 94,5 \\
\hline 4 & 4 & 35 & 71,0 & 47,0 & 97,5 \\
\hline
\end{tabular}

* Delineamento em quadrado latino 4 x 4, com três repetições, em que as linhas representaam os lotes de sementes (Blocos 1, 2, 3 e 4) e as colunas o número de dias $(0,1,2,3$ e 4$)$ em que as sementes permaneceram estocadas antes da secagem; ** Secagem à sombra.

Os resultados referentes às variáveis dos testes de vigor ( $1^{\text {a }}$ contagem e Vigor das plântulas), de germinação (Germinação), teor de água imediatamente depois da secagem (ADS), e aos 90 e 180 dias de armazenamento (AD90 e AD180), avaliadas em função da temperatura de secagem, encontram-se na Tabela 3. Observa-se que para a variável $1^{\text {a }}$ contagem houve efeito significativo dos tratamentos, ou seja, o contraste entre as sementes secadas à sombra e aquelas secadas no secador com temperatura controlada foi significativo. Verifica-se que o vigor das sementes secadas em temperatura controlada foi significativamente superior ao daquelas secadas à temperatura ambiente. A análise de regressão dos valores de germinação na primeira contagem, em função da temperatura de secagem artificial apresentou resultado significativo para um modelo de ordem linear ascendente. Sendo assim, quanto mais alta foi a temperatura de secagem, maior foi o vigor das sementes de maracujá, no intervalo entre 30 e $40^{\circ} \mathrm{C}$. 
TABELA 3. Médias, coeficientes de variação (CV) e níveis descritivos de probabilidade dos contrastes ortogonais para todas as variáveis em função das condições de secagem das sementes

\begin{tabular}{|c|c|c|c|c|c|c|c|c|}
\hline \multirow[t]{2}{*}{ Variável } & \multicolumn{4}{|c|}{ Tratamento } & & \multicolumn{3}{|c|}{ Valor $-\mathrm{P}^{\mathrm{1} /}$} \\
\hline & Sombra & $30{ }^{\circ} \mathrm{C}$ & $35^{\circ} \mathrm{C}$ & $40{ }^{\circ} \mathrm{C}$ & $\mathrm{CV}(\%)$ & Contraste & $\mathrm{L}$ & $\mathrm{Q}$ \\
\hline $1^{\mathrm{a}}$ contagem $(\%)$ & 21,0 & 23,8 & 41,4 & 38,1 & 22,0 & 0,0146 & 0,0249 & 0,1263 \\
\hline Vigor das plântulas (\%) & 17,9 & 12,3 & 27,3 & 26,4 & 30,0 & 0,3025 & 0,0190 & 0,0363 \\
\hline Germinação (\%) & 93,4 & 91,3 & 89,5 & 94,1 & 7,4 & 0,6721 & 0,5726 & 0,9656 \\
\hline $\operatorname{ADS}(\%$ b.u. $)$ & 10,8 & 9,8 & 9,6 & 9,6 & 7,9 & 0,0408 & 0,6650 & 0,4805 \\
\hline AD90 (\% b.u.) & 9,3 & 9,0 & 8,9 & 8,7 & 2,7 & 0,0085 & 0,0332 & 0,1834 \\
\hline AD180 (\% b.u.) & 10,3 & 9,8 & 9,6 & 9,4 & 6,2 & 0,0971 & 0,0643 & 0,5811 \\
\hline
\end{tabular}

1/ Probabilidade $(\mathrm{P})$, a 5\%, para o contraste entre secagem à sombra e secagem artificial; L e Q = efeitos de ordem linear e quadrática, respectivamente, relativos às temperaturas de secagem artificial.

Para a variável germinação aos 14 dias (vigor das plântulas), a análise de variância demonstrou que o efeito da temperatura foi significativo; porém, de acordo com os dados apresentados na Tabela 3, o contraste entre a secagem à sombra e a secagem nas demais temperaturas não foi significativo, indicando que o vigor das plântulas provenientes de sementes submetidas à secagem em condição ambiente foi igual àquele que se obteve na secagem artificial com temperatura controlada. Entretanto, a análise de regressão mostrou novamente que existe uma relação linear entre os dados de vigor e a temperatura de secagem artificial. A análise de variância também mostrou que a temperatura de secagem não teve efeito significativo sobre o percentual de germinação total; isso atesta que o percentual de germinação, para as condições estudadas, independe se a semente é secada à sombra, ou em temperatura controlada no intervalo entre 30 e $40^{\circ} \mathrm{C}$.

O exame conjunto dos resultados relativos aos testes de vigor e germinação apresentados na Tabela 3 permite concluir que tanto a secagem à sombra quanto a secagem artificial realizada com temperatura controlada entre 30 e 40 ${ }^{\circ} \mathrm{C}$ influenciam no vigor das sementes apenas no início da germinação, quando as sementes ainda estão emitindo a raiz primária. Passados alguns dias, o vigor das plântulas secadas em temperatura ambiente ou em secador com temperatura controlada, nos limites estudados, tende a se igualar.

Quanto ao teor de água depois da secagem (ADS), Tabela 3, a análise de variância indicou que o teor de água imediatamente depois da secagem foi estatisticamente igual para todas as amostras de sementes, independente da temperatura utilizada para sua secagem. Contudo, a análise de regressão evidencia que há diferença significativa quando se contrasta a secagem à sombra e a secagem artificial. Na análise de variância referente aos teores de água das sementes aos 90 e 180 dias de armazenamento (AD90 e AD180), observouse que o efeito da interação entre os fatores temperatura $v s$ embalagem não foi significativo. Desta forma, foi necessário fazer a análise desses fatores separadamente, ou seja, em função da temperatura e tipo de embalagem. Para a variável AD90, nota-se que o contraste foi significativo, evidenciando que depois do período de armazenamento de 90 dias, o teor de água das sementes secadas à sombra encontrava-se superior ao das sementes secadas no secador. Além disso, depois deste período de armazenamento, constatou-se que a relação entre o teor de água das sementes secadas no secador e a temperatura de secagem foi descrita por uma equação de ordem linear com declividade negativa, ou seja, quanto maior a temperatura de secagem das sementes, menor foi o teor de água final após o armazenamento. A diferença no teor de água final destas sementes pode ter ocorrido devido ao fato de sua determinação haver sido feita cerca de 60 dias depois da abertura das embalagens para efetuação dos testes de qualidade fisiológica. Deve-se considerar também que depois da abertura das embalagens e montagem dos testes de qualidade fisiológica, as sementes foram acondicionadas à temperatura ambiente e não em câmara do tipo B.O.D. à $15{ }^{\circ} \mathrm{C}$ como haviam estado anteriormente. Para a variável AD180 o contraste não foi significativo, evidenciando que 
depois de 180 dias de armazenamento, tanto as sementes secadas à temperatura ambiente quanto em secador possuíam o mesmo teor de água. Como a determinação do teor de água foi feita imediatamente depois da montagem dos testes de viabilidade das sementes, o parâmetro teor de água não foi alterado.

Os teores de água depois de 90 dias de armazenamento em embalagem de vidro e polietileno foram de 9,1 e $8,9 \%$ b.u., respectivamente, com probabilidade $\mathrm{P}=0,1601$. Os valores correspondentes para 180 dias de armazenamento foram de 9,7 e $9,9 \%$ b.u. $(P=0,2211)$. Os contrastes ortogonais permitiram concluir que não houve relação significativa entre as variáveis AD90 e AD180 e os tipos de embalagem; esse resultado mostra que, independentemente das embalagens utilizadas, vidro ou plástico, o teor de água das sementes depois de 90 e 180 dias de armazenamento manteve-se estatisticamente igual. Desta forma, é possível conjecturar que os dois tipos de embalagem utilizados no experimento impediram que houvessem trocas de vapor d'água entre o meio interno e o externo. No caso do vidro, esse resultado era esperado, pois trata-se de embalagem impermeável. Para o saco plástico, como o seu grau de impermeabilidade não foi medido, não se sabia a priori se o teor de água seria alterado ou não. Esses resultados confirmam aqueles obtidos por Martins et al. (2005), que também observaram estabilidade nos valores de teor de água de sementes de maracujá amarelo armazenadas por 315 dias em sacos de polietileno com 0,14 mm de espessura.

Os resultados obtidos na terceira etapa da análise estatística permitem concluir que não houve efeito significativo da temperatura de secagem sobre o vigor $\left(1^{\text {a }}\right.$ contagem) e sequer sobre o percentual total de germinação (Germinação), como mostra a Tabela 4. Esse resultado referente à contagem aos sete dias contradiz aquele observado na Tabela 3, porém, é importante ressaltar, que na primeira análise as variáveis foram testadas somente quanto ao efeito da temperatura, enquanto que na terceira análise o foram também para o período de armazenamento e o tipo de embalagem. Os períodos de 90 e 180 dias de armazenamento não influenciaram o vigor ( $1^{\mathrm{a}}$ contagem) nem o percentual total de germinação. Os valores médios da $1^{\text {a }}$ contagem da germinação, para sementes armazenadas por 90 e 180 dias, a $15{ }^{\circ} \mathrm{C}$, foram de 76,0 e $75,8 \%$, respectivamente $(\mathrm{P}$ $=0,9577)$. Os valores correspondentes para Germinação foram de 92,4 e $91,5 \%(P=0,3313)$. Os valores médios da $1^{\text {a }}$ contagem da germinação e o percentual total de germinação obtidos para sementes armazenadas por 180 dias, a $15{ }^{\circ} \mathrm{C}$, diferem dos obtidos por Martins et al. (2005) aos 175 dias de armazenamento, a 10 e $20{ }^{\circ} \mathrm{C}$, que foram de 40 e $66 \%$ e de 47 e $66 \%$, respectivamente, porém mostram, similarmente ao afirmado por Zampieri (1982), que o período de armazenamento influencia efetivamente a capacidade de germinação e o vigor das sementes de maracujá.

TABELA 4. Médias, coeficientes de variação (CV) e níveis descritivos de probabilidade para os contrastes ortogonais para as variáveis $1^{\mathrm{a}}$ contagem, Germinação e períodos de armazenamento de 90 e 180 dias em função das condições de secagem das sementes.

\begin{tabular}{|c|c|c|c|c|c|c|c|c|}
\hline \multirow{2}{*}{ Variável } & \multicolumn{4}{|c|}{ Tratamento } & \multirow{2}{*}{$\begin{array}{l}\text { CV } \\
(\%)\end{array}$} & \multicolumn{3}{|c|}{ Valor - $\mathrm{P}^{1}$} \\
\hline & Sombra & $30^{\circ} \mathrm{C}$ & $35^{\circ} \mathrm{C}$ & $40{ }^{\circ} \mathrm{C}$ & & Contraste & $\mathrm{L}$ & $\mathrm{Q}$ \\
\hline $1^{\mathrm{a}}$ contagem & 73,2 & 71,5 & 77,5 & 81,2 & 21,3 & 0,3667 & 0,1395 & 0,8192 \\
\hline Germinação & 91,9 & 92,2 & 91,6 & 92,2 & 3,9 & 0,9459 & 0,9658 & 0,6492 \\
\hline
\end{tabular}

Para o fator embalagem, não observou-se influência na Tabela 5. Esses resultados diferem daqueles obtidos por significativa sobre o vigor estimado tanto pela primeira Catunda etal.(2003), que armazenaram sementes de maracujá contagem quanto no vigor das plântulas, nem sobre o por dez meses em condições controladas de temperatura (18 percentual total de germinação, como pode ser constatado $\left.{ }^{\circ} \mathrm{C}\right)$ e UR $(24 \%)$ e encontraram resposta quadrática para a 
germinação das sementes que estavam acondicionadas em embalagem impermeável. Porém, são similares aos valores obtidos por Lima et al. (1991), que armazenaram sementes de maracujá em refrigerador com temperatura controlada entre 5 e $10{ }^{\circ} \mathrm{C}$, em recipientes de vidro, isopor, lata e saco de polietileno escuro, por um período de 180 dias, e não encontraram diferença significativa entre os percentuais de germinação e vigor obtidos para os diferentes tipos de embalagem.

TABELA 5. Médias, coeficientes de variação (CV) e níveis descritivos de probabilidade para os contrastes ortogonais para as variáveis $\mathbf{1}^{\mathrm{a}}$ contagem, Vigor das plântulas e Germinação em função das condições de armazenamento das sementes

\section{Embalagem}

\begin{tabular}{lcccc}
\hline Variável & Plástico & Vidro & CV (\%) & Valor - P \\
\hline $1^{\text {a }}$ contagem & 74,0 & 77,8 & 18,50 & 0,2886 \\
\hline $\begin{array}{l}\text { Vigor das } \\
\text { plântulas }\end{array}$ & 47,7 & 50,7 & 25,40 & 0,3433 \\
\begin{tabular}{l} 
Germinação \\
\hline
\end{tabular} & 92,0 & 91,9 & 4,10 & 0,8554 \\
\hline
\end{tabular}

Para a variável contagem aos 14 dias, os resultados da análise de variância mostraram que a interação da temperatura $v s$ armazenamento foi significativa. Porém, depois de realizar o desdobramento da interação, não foram encontrados resultados significativos para o contraste secagem à sombra vs secagem artificial, nos períodos de 90 e 180 dias de armazenamento $(\mathrm{P}=0,1375$ e 0,9470, respectivamente); apesar disso, observou-se uma relação linear positiva entre a temperatura de secagem artificial e o percentual de germinação, para o período de armazenamento de 90 dias.

\section{CONCLUSÕES}

A secagem das sementes de mamão pode ser realizada à sombra ou em temperaturas de 30 a $40{ }^{\circ} \mathrm{C}$, sem afetar a qualidade fisiológica das mesmas.

As sementes podem ser embaladas em recipientes de vidro ou polietileno, por períodos de 90 e 180 dias, sem afetar a sua qualidade fisiológia e o vigor das plântulas.

\section{REFERÊNCIAS}

ALMEIDA, A.M.; NAKAGAWA, J.; ALMEIDA, R.M. Efeito do armazenamento na germinação de sementes de maracujá amarelo de diferentes estádios de maturação. Experimento I. In: CONGRESSO BRASILEIRO DE FRUTICULTURA, 9., 1987, Campinas. Anais... Pelotas: Sociedade Brasileira de Fruticultura, 1987. p.603-607.

ALMEIDA, L.P.; BOARETTO, M.A.C.; SANTANA, R.G.; NASCIMENTO, G.M.; SOUZA, P.J.; JOSÉ, A.R.S. Estaquia e comportamento de maracujazeiros (Passiflora edulis SIMS f. flavicarpa Deg.) propagados por vias sexual e vegetativa. Revista Brasileira de Fruticultura, Jaboticabal, v.13, p.153-156. 1991.

BRASIL. Ministério da Agricultura e Reforma Agrária. SNDA/DNDV/CLAN, Regras para análise de sementes. Brasília, DF, 1992. 365p.

BRUCKNER, C.H.; PICANÇO, M.C. Maracujá: tecnologia de produção, pós-colheita, agroindústria, mercado. Porto Alegre: Cinco Continentes, 2001, 472p.

CATUNDA, P.H.A.; VIEIRA, H.D.; SILVA, R.F.; POSSE, S.C.P. Influência do teor de água, da embalagem e das condições de armazenamento na qualidade de sementes de maracujá-amarelo. Revista Brasileira de Sementes, Pelotas, v. 25, p.65-71, 2003.

LIMA, A.A.; TRINDADE, A.V. Propagação. In: LIMA, A.A. (Org.). Maracujá produção: aspectos técnicos. Brasília, DF: Embrapa Informação Tecnológica, 2002. p. 29-33.

LIMA, D.; BRUNO, R.L.A.; LIMA, A.A.; CARDOSO, E.A. Efeito de recipientes e de dois ambientes de armazenamento sobre a germinação e vigor de sementes de maracujazeiro amarelo (Passiflora edulis Sims f. flavicarpa Deg.). Revista Brasileira de Fruticultura, Jaboticabal, v. 13, p. 27-32, 1991.

MARTINS, L.; SILVA, W.R.; MELETTI, L.M.M. Conservação de sementes de maracujá-amarelo (Passiflora edulis SIMS F. flavicarpa deg.). Revista Brasileira de Sementes, Pelotas, v. 27, n.1, p.183-189, 2005.

MELO, E.C.; LOPES, D.C.; CORRÊA, P.C. GRAPSI Programa computacional para o cálculo das propriedades psicrométricas do ar. Engenharia na Agricultura, Viçosa, v. 12, p.145-154, 2004.

NAKAGAWA, J.; CAVARIANI, C.; AMARAL, W.E.N. Armazenamento de sementes de maracujá amarelo. Revista Brasileira de Fruticultura, Jaboticabal, v. 13, p. 77-80, 1991.

OLIVEIRA, J.C.; SADER, R.; ZAMPIERI, R.A. Efeito da 
idade sobre a emergência e vigor de sementes de maracujáamarelo. Revista Brasileira de Sementes, Brasília, v. 6, n. 2, p.37-43, 1984.

RUGGIERO, C. Maracujá: do plantio à colheita. Jaboticabal: Funep/Unesp, 1998. 388p.

SOUZA, J.S.; CARDOSO, C.E.L.; LIMA, A.A.; COELHO, E.F. Aspectos sócio econômicos. In: LIMA, A.A. (Ed.).
Maracujá - produção: aspectos técnicos. Brasília, DF: Embrapa Informação Tecnológica, 2002. p.10.

ZAMPIERI, R.A. Efeito da idade sobre a capacidade de emergência e vigor de sementes de maracujá amarelo (Passiflora edulis Sims. f. flavicarpa Deg.). 1982. 34f. Monografia (Graduação em Ciências Agrárias)-Universidade Estadual Paulista “Júlio de Mesquita Filho”, Jaboticabal. 